\title{
Duodenal Perforation Secondary to Migrated Biliary Stent: A Rare and Serious Complication of Endoscopic Retrograde Cholangiopancreatography
}

Vipul D. Yagnik, Vismit P. Joshipura ${ }^{1}$

Department of Surgical Gastroenterology, Ronak Endo-laparoscopy and General Surgical Hospital, Patan, ${ }^{1}$ Department of Surgical Gastroenterology, Vivan Hospital, Ahmedabad, Gujarat, India Although migration of biliary stents is not uncommon, stent-induced perforation of the intestinal wall is a rare and serious complication. We report a case of duodenal perforation secondary to migrated biliary stent kept for obstructive jaundice for common bile duct stone in a 64-year-old male. Intestinal perforation secondary to migrated stent should be considered in patients reported with abdominal pain and sepsis after an endoscopic retrograde cholangiopancreatography with biliary stent placement.

KEYWORDS: Biliary stent, duodenal perforation, endoscopic retrograde cholangiopancreatography

\section{INTRODUCTION}

$\mathcal{E}$ ndoscopic retrograde cholangiopancreatography (ERCP) with biliary stenting is widely used as a well-established procedure for benign or malignant biliary tract obstruction. Although the migration of plastic biliary stents has been reported, stent-induced perforation of the intestinal wall is an uncommon complication. Computed tomography (CT) is the diagnostic procedure of choice that locates the stent, the presence of perforation, and other complications, and also helps in establishing the treatment options. This report presents a rare case of migrated biliary stent where the cranial part of the stent remained in the common bile duct (CBD) stone and the caudal part perforated the second part of duodenum, causing a retroperitoneal abscess.

\section{CASE Report}

A 64-year-old male presented with abdominal pain, vomiting, and yellow discoloration of his eyes and urine over a week prior to presentation. He reported no significant history of weight loss, and there was no alteration in the color of his stool. All blood investigations were within the reference range except a serum bilirubin level of $8 \mathrm{mg} / \mathrm{dL}$ and a serum alkaline phosphatase level of $800 \mathrm{U} / \mathrm{L}$. Abdominal ultrasonography (USG) revealed a CBD stone measuring

\begin{tabular}{|l|l|}
\hline \multicolumn{2}{|c|}{ Access this article online } \\
\hline Quick Response Code: & Website: www.jdeonline.in \\
\hline
\end{tabular}

$10 \mathrm{~mm}$ in size with multiple gallbladder stones. Written and informed consent for ERCP was obtained after explaining possible complications associated with ERCP such as pancreatitis, bleeding, infection, and perforation. We performed an ERCP to remove the CBD stone. Cholangiogram revealed mild dilatation of the CBD with a small filling defect at the lower end of CBD. We performed sphincterotomy in this case to remove the stone. After sphincterotomy, over the guidewire, we introduced standard ERCP balloon and passed it beyond the stone till the upper end of bile duct. We inflated a balloon at this point and dragged it down to remove the stone. We inserted a $10 \mathrm{~F} 10-\mathrm{cm}$ straight plastic stent. The stent can be avoided in this particular case, but as the patient was not willing for post-ERCP immediate surgery on the next day, we decided to keep the stent to prevent similar complication in the future. His serum bilirubin level was $2.0 \mathrm{mg} / \mathrm{dL}$ at the time of discharge on the $4^{\text {th }}$ postoperative day. He required re-admission on the $8^{\text {th }}$ postoperative day for severe abdominal pain and sepsis with elevated serum pancreatic enzymes.

Address for correspondence: Dr. Vipul D. Yagnik, 77, Siddhraj Nagar, Rajmahal Road, Patan - 384 265, Gujarat, India. E-mail: vipul.yagnik@gmail.com

This is an open access journal, and articles are distributed under the terms of the Creative Commons Attribution-NonCommercial-ShareAlike 4.0 License, which allows others to remix, tweak, and build upon the work non-commercially, as long as appropriate credit is given and the new creations are licensed under the identical terms.

For reprints contact: reprints@medknow.com

How to cite this article: Yagnik VD, Joshipura VP. Duodenal perforation secondary to migrated biliary stent: A rare and serious complication of endoscopic retrograde cholangiopancreatography. J Dig Endosc 2018;9:193-5. 
Abdominal USG revealed moderate ascites with pancreatic edema. CT could not be performed due to altered renal function. The patient was diagnosed with post-ERCP pancreatitis and treated with nasojejunal tube feeding, administration of broad-spectrum antibiotics, and percutaneous drainage of fluid collections. On the $17^{\text {th }}$ postoperative day, while his sepsis persisted, renal function was shown to have improved. Therefore, abdominal CT was performed which showed that the caudal end of the stent had perforated the lateral wall of the second part of the duodenum with leakage of oral contrast into the right anterior pararenal space [Figure 1]. Further exploration revealed the presence of an abscess in the right retroperitoneal area and the psoas muscle, as well as an $8-\mathrm{mm}$ laceration in the second part of the duodenum with protrusion of the stent through it [Figure 2]. The stent was removed, and a 16F T-tube duodenostomy was performed, followed by insertion of a Jackson-Pratt drain and abdominal tube drain, and a feeding jejunostomy was constructed. The patient required 30 days of hospitalization including 7 days in the Intensive Care Unit. He has had an uneventful course over 6-month follow-up other than the development of an incisional hernia.

\section{Discussion}

Reportedly, the incidence of a perforation associated with an ERCP is $<1 \%{ }^{[1]}$ A perforation could occur secondary to extension of a sphincterotomy beyond the transmural portion of the bile or pancreatic duct, or extramural passage or migration of the guidewire or stent. ${ }^{[1]}$ Risk factors for a perforation include altered surgical anatomy, an inappropriately performed sphincterotomy, stricture dilation, and a lengthy procedure. ${ }^{[2]}$ Howard et al. have classified ERCP-related

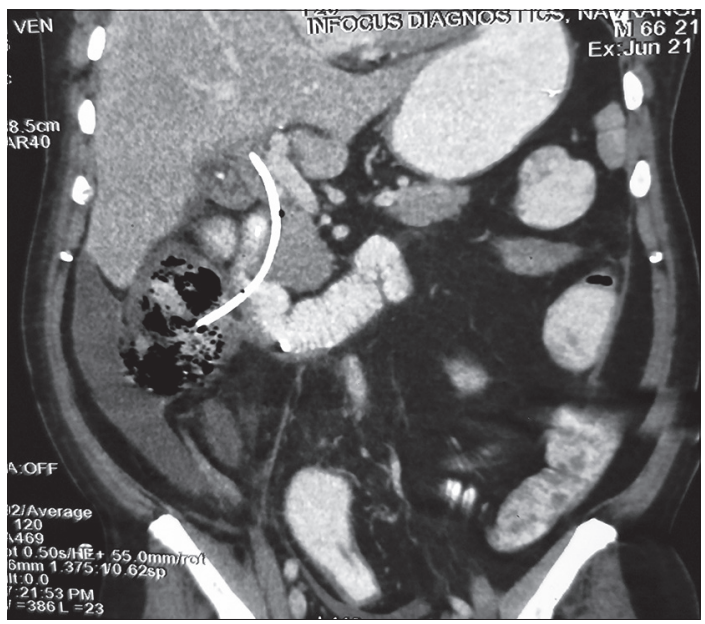

Figure 1: Computed tomography of the abdomen showing migration of the biliary stent causing perforation of the second part of duodenum, with protrusion of the stent into the right anterior pararenal space perforations into three distinct varieties: guidewire induced, peri-ampullary, and duodenal remote from the papilla. ${ }^{[3]}$ Stapfer et al. have classified ERCP-related perforations into four types based on etiology, location of the perforation, and severity of injury as follows: ${ }^{[4]}$ Type I: lateral- or medial-wall duodenal perforations, Type II: peri-ampullary, Type III: injury to the bile duct secondary to the guidewire/basket instrumentation, and Type IV: radiological evidence of free air without any obvious perforation or contrast extravasation.

Arhan et al. have observed that the overall migration rate for plastic stents in patients with benign and malignant diseases is $8.58 \%$ (proximal $4.58 \%$ and distal $4.00 \%$ ) and that stent migration was more commonly associated with benign disease. ${ }^{[5]}$ Although intestinal migration of biliary stents is not uncommon, stent-induced perforation of the intestinal wall is a rare complication. Being a C-shaped structure with a fixed retroperitoneal location, the duodenum is predisposed to higher risk of stent perforation. ${ }^{[6]}$ Other conditions associated with increased risk of stent perforation are the presence of duodenal diverticula and abdominal wall hernias. ${ }^{[5]}$ This case is different in that the cranial part of the stent remained in the CBD and the caudal part perforated the duodenum, causing complete biliary diversion into the retroperitoneal cavity leading to retroperitoneal abscess formation. We have observed that most reported cases of luminal perforation with biliary stents have been associated with a straight biliary stent. ${ }^{[6-10]}$ From the available literature, we suggest that double pigtail stents are to be used to prevent such disastrous complication. Pigtail stents are less likely to migrate distally. They are placed slightly differently than straight plastic stents since duodenoscope has to be partially withdrawn during final deployment to allow the pigtail to form in the second part of the duodenum.

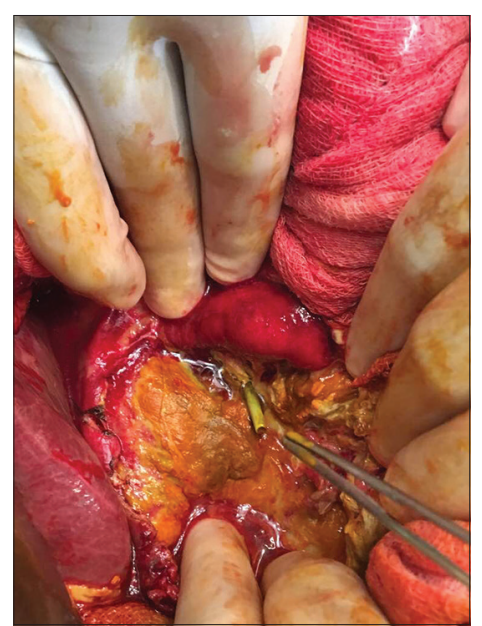

Figure 2: Duodenal perforation secondary to the migrated stent through an $8-\mathrm{mm}$ laceration into the right anterior pararenal space 


\section{Conclusion}

Migration of a plastic biliary stent causing a duodenal perforation is rare. We propose that clinicians should consider this entity among the differential diagnoses in patients presenting with abdominal pain and sepsis after an ERCP with stent placement. This diagnosis should be considered in those presenting with a high index of suspicion. A suspected perforation should be investigated using a CT scan of the abdomen with oral contrast even in cases of altered renal function.

\section{Declaration of patient consent}

The authors certify that they have obtained all appropriate patient consent forms. In the form the patient(s) has/have given his/her/their consent for his/ her/their images and other clinical information to be reported in the journal. The patients understand that their names and initials will not be published and due efforts will be made to conceal their identity, but anonymity cannot be guaranteed.

\section{Acknowledgement}

We would like to acknowledge the help provided by Dr. Sushil Dawka (professor of surgery, Mauritius) for his kind suggestions and helps in editing the manuscript.

\section{Financial support and sponsorship}

Nil.

\section{Conflicts of interest}

There are no conflicts of interest.

\section{REFERENCES}

1. Freeman ML. Adverse event of ERCP prediction, prevention and management. In: Baron TH, Kozarek RA, Car-locke DL, editors. ERCP. $2^{\text {nd }}$ ed. Philadelphia, PA: Elsevier Saunders; 2013.p. 57-65.

2. Loperfido S, Angelini G, Benedetti G, Chilovi F, Costan F, De Berardinis F, et al. Major early complications from diagnostic and therapeutic ERCP: A prospective multicenter study. Gastrointest Endosc 1998;48:1-0.

3. Howard TJ, Tan T, Lehman GA, Sherman S, Madura JA, Fogel E, et al. Classification and management of perforations complicating endoscopic sphincterotomy. Surgery 1999;126:658-63.

4. Stapfer M, Selby RR, Stain SC, Katkhouda N, Parekh D, Jabbour $\mathrm{N}$, et al. Management of duodenal perforation after endoscopic retrograde cholangiopancreaticography and sphincterotomy. Am Surg 2000;232:191-8.

5. Arhan M, Odemiş B, Parlak E, Ertuğrul I, Başar O. Migration of biliary plastic stents: Experience of a tertiary center. Surg Endosc 2009;23:769-75

6. Humar A, Barron PT, Sekar AS, Lum A. Pancreatitis and duodenal perforation as complications of an endoscopically placed biliary stent. Gastrointest Endosc 1994;40:365-6.

7. Størkson RH, Edwin B, Reiertsen O, Faerden AE, Sortland O, Rosseland AR, et al. Gut perforation caused by biliary endoprosthesis. Endoscopy 2000;32:87-9.

8. Yilmaz Ö, Kiziltan R, Aydin O, Bayrak V, Kotan Ç. A rare complication of biliary stent migration: Small bowel perforation in a patient with incisional hernia. Case Rep Surg 2015. DOI:https://doi.org/10.1155/2015/860286.

9. Elliott M, Boland S. Sigmoid colon perforation following a migrated biliary stent. ANZ J Surg 2003;73:669-70.

10. Rosés LL, Ramirez AG, Seco AL, Blanco ES, Alonso DI, Avila S, et al. Clip closure of a duodenal perforation secondary to a biliary stent. Gastrointest Endosc 2000;51:487-9. 